\title{
New apparatus to provide repeatable surface temperature-time treatments on inoculated food samples
}

\author{
Alan M Foster ${ }^{\text {a,* }}$, Laurence P Ketteringham ${ }^{\text {a }}$, Graham L Purnell ${ }^{\text {a }}$ \\ Alain Kondjoyan ${ }^{\mathrm{b}}$, Michel Havet ${ }^{\mathrm{c}}$ and Judith A Evans ${ }^{\mathrm{a}}$ \\ ${ }^{\text {a }}$ FRPERC, University of Bristol, Churchill Building, Langford, Bristol, BS40 5DU, UK \\ ${ }^{\mathrm{b}}$ INRA, Station de Recherches sur la Viande, 63122 St Genès Champanelle, France \\ ${ }^{\mathrm{c}}$ ENITIAA, rue de la Géraudière, BP 82225, 44322 Nantes cedex 3, France \\ *Corresponding author, Tel: +44 (0)117928 9281, E-mail:a.m.foster@bristol.ac.uk
}

Key words

Food poisoning, surface decontamination, microbial models, heating and cooling equipment, surface temperature measurement.

\begin{abstract}
The final stage of the BUGDEATH project (James and Evans, 2005) was to further develop the surface heating and cooling apparatus so it would be suitable for commercial exploitation. The new apparatus can be accommodated on a bench top and produces faster more uniform heating and cooling cycles than that previously described. It can heat the surface of a food from 8 to $120^{\circ} \mathrm{C}$ in $14 \mathrm{~s}$, cool from $120^{\circ} \mathrm{C}$ to $40^{\circ} \mathrm{C}$ in $28 \mathrm{~s}$ and then to $8^{\circ} \mathrm{C}$ in 5 minutes. There is an average control error of approximately $\pm 1^{\circ} \mathrm{C}$ and a temperature variation over the surface of the sample of only $1.2^{\circ} \mathrm{C}$. Wet heating, using steam at $100^{\circ} \mathrm{C}$, was achieved using a portable steam generator. The price of the parts which made up the apparatus were approximately $€ 10000$ and it takes approximately two person-weeks to build.
\end{abstract}




\section{Introduction}

The design, construction and performance of the original apparatus developed as part of the BUGDEATH project (James and Evans, 2005) to provide controlled heating and cooling cycles at the surface of food samples is described by Foster et al (2005). This paper describes improvements that were made to the apparatus, as a result of feedback from the project partners who used the apparatus and knowledge gained in designing, building and using the original apparatus.

The aim of the improvements was to create a piece of commercially viable equipment for exploitation after the end of the project.

\section{Improved apparatus specification}

In consultation with the partners who were using the original apparatus a 'wish list' of improvements was produced for a 'commercial' system. From this wish list a final specification was produced.

The final specification was that the:

- Apparatus should cost less than $€ 15000$ to build.

- Apparatus should be small enough to be bench mounted. The steam generator and cooler would be separate units, but bench mountable.

- Entire chamber should be capable of withstanding $200^{\circ} \mathrm{C}$ for 3 minutes and $120^{\circ} \mathrm{C}$ for 3 hours.

- Sample should be viewable through glass panels at any point in any process. 
- Software should control the surface temperature by a straight-line ramp as in the previous apparatus.

- Controller should be a PC with a graphical user interface (GUI) to make it easy to use.

- Apparatus should be capable of heating the surface of a sample from 0 to $120^{\circ} \mathrm{C}$ in 20 s using dry air (fastest uncontrolled heating).

- Un-pressurised apparatus should be able to heat the sample using saturated steam or superheated steam up to $120^{\circ} \mathrm{C}$.

- Apparatus should be able to cool the surface of a sample from $120^{\circ} \mathrm{C}$ to $40^{\circ} \mathrm{C}$ in $15 \mathrm{~s}$ and then to $5^{\circ} \mathrm{C}$ in 5 minutes.

- Apparatus should control the surface temperature to an accuracy of $\pm 0.5^{\circ} \mathrm{C}$ and uniformity of $\pm 1^{\circ} \mathrm{C}$.

- Apparatus should operate from a 32 A single-phase electrical supply and only require compressed air for the cooling.

- Process velocities over the sample should be less than $20 \mathrm{~m} \cdot \mathrm{s}^{-1}$ to avoid the possibility of bacteria being blown off the surface.

- Chamber did not need high efficiency particulate air (HEPA) filtration, however, exhaust nozzles should be provided to allow a filtration system to be easily attached.

- Cooling should be possible immediately after a steam treatment.

\section{Development of system}

It was evident from the previous apparatus that providing all the processes in one chamber made cooling more difficult. This was because the cooling nozzle was heated by, but could 
not be cooled during, the heating treatment. In the previous apparatus, the heating and cooling air and steam were delivered parallel (slightly above and from the side) to the rotating sample. However, despite sample rotation the whole of the surface was not uniformly heated.

The heat transfer mathematical model developed in the project (Kondjoyan, Rouaud, McCann, Havet, Foster, Swain et al, 2005) was used to aid in the design of the equipment and specify the heating and cooling treatments required.

To improve the rate of cooling and uniformity of heating the new system was designed with four chambers (quadrants) and the heating or cooling medium introduced perpendicular to the surface of the sample.

Air impingement techniques were used to enhance uniformity of surface temperature and produce faster heating rates (Soto \& Borquez, 2001). To minimise the effect of the environment on the process jet due to entrainment, two design rules were followed. 1) The diameter of the process nozzle was at least as large as the diameter of the sample and 2) the nozzle was a distance of less than 5 nozzle diameters away from the surface of the sample. A distance of five nozzle diameters from the nozzle has been shown to be where the potential core of the jet ends (Rajaratnam, 1976). The potential core is the central region of the jet that is unaffected by the entrainment and so not subject to a temperature drop.

Allowing the treatment nozzle to be placed directly above the sample surface meant that the IR thermometer could not also be placed directly above the surface, as in the previous apparatus (Figure 1). The measurement of surface temperature is explained in more detail in Section 4.5 .

The diameter of the sample was now critical to the design of the apparatus. A smaller sample diameter would reduce the size of many key elements, including the nozzle diameter. It 
would also reduce the airflow rate, for a given velocity, and therefore the power of the heater required to provide the same temperature in the hot air stream. A borosilicate glass Petri dish (237553903, Schott AG, Mainz, Germany) with an external diameter and height of 40 and 12 mm, respectively, was chosen. This was the smallest standard size available, which provided a large enough surface to inoculate with bacteria.

In the new system the treatments were carried out in separate quadrants (Figure 1). The chamber was constructed from aluminium (320 mm x 320mm x $260 \mathrm{~mm}$ high) and split into quadrants for the different processes (loading, heating, cooling, steam). One outer side of each quadrant contained toughened glass panels through which the process could be viewed. These panels were removable for access. To move he sample dish through the different treatment quadrants it was held (friction fit) on an aluminium support connected to a threaded rod, which was in turn attached to the central spindle. The threaded rod ensured correct alignment of the sample under the treatment nozzles.

A $230 \mathrm{~V}, 32$ A mains socket provided all the electrical services required by the main apparatus. The refrigeration system and steam generator required one extra $230 \mathrm{~V}$ and $13 \mathrm{~A}$ main sockets each. Compressed air was also needed by the refrigeration system, which could come from either a compressed air line or a compressed air cylinder. The overall dimensions of the apparatus were $0.5 \times 0.8 \times 1.1 \mathrm{~m}$ In addition space was required for a computer, a refrigeration system $(0.46 \times 0.6$ x $0.6 \mathrm{~m})$ and a steam generator ( 0.3 diameter x $0.4 \mathrm{~m})$.

\section{Process and control}

Figure 1 shows a schematic of the chamber and treatment processes. There were three different treatment processes, steam, hot air and cold air, each carried out in a separate section of the chamber. A sample was initially placed in the loading section of the chamber. 
When the start button on the GUI was pressed, the sample was rotated into whichever section of the chamber was required at that time i.e. dry heating, cooling or steam. The rotation was carried out by a bipolar stepper motor (5-595, Milford Instruments Ltd, Leeds, UK).

To avoid problems with condensation from the steam treatment running into the motor, screw holes were minimised in the base plate of the chamber, and the stepper motor was offset via a drive belt and pulley system, which also allowed gearing for extra torque. The central axis of the chamber rotated on a top hat flange bearing.

\subsection{Steam treatment}

A steam cleaner (Vaporetto Ecopro 3000 lux, Polti Spa, Como, Italy) with a $2.2 \mathrm{~kW}$ element was used to generate steam at 3.5 bar pressure. The steam cleaner was modified such that the discharge valve was controlled automatically from the apparatus and the discharge pipe was modified to connect to the top of the steam section of the chamber.

Steam was exhausted over the sample from above driven by the pressure in the generator. Exhaust steam was vented from a port under the chamber and ducted away to avoid waste steam damaging the electronics.

\subsection{Hot air treatment}

Ambient air was blown through a high-pressure regenerative blower into a $3.6 \mathrm{~kW}$ heater (Robust and Heater 3300 respectively, Leister Process Technologies, Sarnen, Switzerland) and then into the top of the 'dry air heating' section of the chamber. The hot air was exhausted through a nozzle $160 \mathrm{~mm}$ long and $36.5 \mathrm{~mm}$ diameter positioned $130 \mathrm{~mm}$ above the sample. 


\subsection{Cold air treatment}

Cold air was generated by passing compressed air through a refrigeration evaporator (011221, ACR Heat transfer Ltd, Norfolk, UK). The evaporator was designed to give a $30 \mathrm{~K}$ temperature reduction at an airflow rate of $0.012 \mathrm{~m}^{3} \cdot \mathrm{s}^{-1}$. It was connected to a condensing unit (CAE9460ZMHR, L’Unite-Hermetique, Barentin, France) designed to remove $1.2 \mathrm{~kW}$ of heat at $0^{\circ} \mathrm{C}$. The complete refrigeration unit was specified to cool the air to $0^{\circ} \mathrm{C}$ and no lower, to avoid ice build-up in the cold air delivery pipe, which was a problem in the previous apparatus. An aluminium chamber housing the evaporator chamber had inlet and outlet ports to take air from the compressed air line via a filter drier, volume flow valve and solenoid valve and deliver air into the chamber via a $38 \mathrm{~mm}$ diameter PVC hose. Both the evaporator and hose were insulated using rubber insulation (Armaflex, Armstrong Insulation products, Lancs., UK).

\subsection{Temperature control}

The user entered a 'temperature at start of heating', 'temperature at end of heating', 'heating duration' and 'holding duration' into the GUI. The control and logging program converted this into a heating and holding ramp as described in Foster et al., (2005). This ramp defined the desired surface temperature history of the sample.

The control program contained five control mechanisms, standard, differential, double differential and integral control, plus a wait timer. The control mechanisms had different purposes. Differential and double differential controls damped the transient nature of the heating and cooling by adding an element of anticipation. The integral control counteracted the effect of heating being faster than cooling, which led to oscillation of the surface temperatures, which were, on average, above the control temperature. While the wait timer forced the heating event to wait for a given time after each heating pulse to reduce overshoot 
of surface temperature. These control mechanisms could be switched on or off, depending on whether they provided better control for that particular treatment.

The standard control was the same as that used in the previous apparatus. During heating and holding, if the surface temperature (temperature measured by the IR thermometer) was below the desired control temperature, the heater would be turned on, if above, the heating would be turned off. Cooling worked in the opposite way; if the surface temperature were above the control temperature the cooling valve would be opened, if below it would be closed.

Differential control extrapolated the future surface temperature from the current temperature and gradient (obtained from the current and previous surface temperatures) and compared it with the future control temperature. It then turned the heating on or off depending on whether the future surface temperature was above or below the future control temperature. How far the control program looked into the future could be modified.

Double differential control worked in a similar way to differential control except that it used the last two gradients and their rate of change (obtained from the current and previous surface temperatures) to predict the future temperature.

Integral control worked by averaging the error between the surface temperatures and control temperatures over the last 100 control points (approximately $10 \mathrm{~s}$ ), then offsetting the control temperature by the negative of the average error.

The wait timer forced the controller to wait for a given time after each $0.1 \mathrm{~s}$ “on” pulse. This was to allow the lag between the control action and the surface temperature change to occur before the next decision about giving an "on” pulse was made.

Depending on the heating rate and type of sample, control variables were changed (tuned) to give a more accurate control of surface temperature. 


\subsection{Measurement of Process conditions}

A 16 channel analogue input measurement processor (Datascan 7320, Measurement Systems Ltd, Newbury, UK) recorded the temperature of each of the treatment conditions and also the temperature of the product surface. Temperatures of the hot air, steam and cold air at the exit of the nozzles were measured using bare welded thermocouples made from $0.2 \mathrm{~mm}$ diameter wire (Type-K).

The surface temperature was measured, to an accuracy of $\pm 0.2^{\circ} \mathrm{C}$, using an infra-red (IR) thermometer (RAYGPSCFL, Raytek UK, Buckinghamshire, UK) and monitor (RAYGPCM, Raytek UK, Buckinghamshire, UK). The IR thermometer measured the temperature of the surface defined by the 'spot diameter'. The relationship between the spot diameter and the distance from the sensing head of the thermometer was defined by the optics of the sensor lens. The sensor had close focus optics, meaning that the distance from the sensor head to the product surface was 45 times larger than the spot diameter. It could therefore be positioned outside the chamber (looking through a hole in the top of the chamber) and at an angle to the sample, to avoid the base of the process nozzle. The optics initially converged before diverging, allowing the size of the hole in the top of the chamber to be minimised. The sensor contained laser sighting to allow accurate positioning. It was assumed that all samples had an emissivity of 0.95 .

All of the sensor outputs were recorded every $0.1 \mathrm{~s}$ and logged in an output file.

The velocity of the air exiting the process nozzles was measured using a hot wire anemometer (Testo 425, Testo Ltd, Hampshire, UK). 


\subsection{Control and logging}

A 16 channel digital output expansion module (Datascan 7035, Measurement Systems Ltd, Newbury, UK) was connected to the analogue measurement processor and was used to switch devices on or off.

The control and logging program was compiled and installed on a personal computer (PC) (Pentium 3/1.0GHz, Viglen Ltd, Middlesex, UK) connected to the analogue input processor via an RS232 cable. It controlled the process treatments and movement of the sample and logged the measured data to disk. The program received information on the state of the process from the analogue measurement processor and controlled the process by setting the state of switches on a digital output processor.

A GUI, written in Microsoft ${ }^{\circledR}$ Visual Basic 6, to make the apparatus safe and easy to use and allow process variables to be set in a user-friendly way. There were four choices of treatment process:

- 'Dry heating only'

- 'Dry heating plus cooling'

- 'Wet heating' (steam)

- 'Wet heating plus cooling'

The variables entered by the user for the 'Dry heating only' process were the temperature at the start of heating, temperature at end of heating, heating and holding duration. Identical variables were entered for the 'Dry heating and cooling' process with the addition of the temperatures at the end of stage 1 and 2 cooling and the cooling durations for both stage 1 and 2. The 'Wet heating' process only required the user to input the heating duration, as surface temperature was not controlled during this process. 


\subsection{Calibration}

All the process thermocouples were calibrated in a stirred water bath between 25 and $95^{\circ} \mathrm{C}$ against a platinum resistance thermometer (Digitron 2024T, Sifam Instruments Ltd, Devon, UK), calibrated to national standards. Both IR thermometers were calibrated using the same slow heating method for an aluminium sample, as in the previous apparatus (Foster et al, 2005).

\section{Performance}

\subsection{Dry heating/cooling}

The velocity of the air exiting the hot air nozzle was measured as $12( \pm 1) \mathrm{m} \cdot \mathrm{s}^{-1}$. This dropped

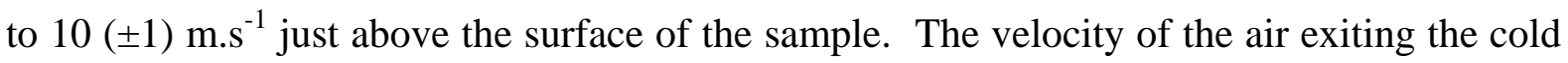
air nozzle was adjusted by a valve in the compressed air line such that the velocity over the surface was initially at $20 \mathrm{~m} . \mathrm{s}^{-1}$, however, this velocity dropped with time (a $4 \mathrm{~m} . \mathrm{s}^{-1}$ drop over the first $60 \mathrm{~s}$ ) due to the characteristics of the compressed air system.

The 'maximum heating' setting heated the sample as quickly as possible to a target temperature, instead of in a straight-line ramp. When set to 'maximum heating', initial trials showed that the apparatus could heat the surface of a test substance 'Tylose' (Riedel, 1960) from 8 to $120^{\circ} \mathrm{C}$ in $23 \mathrm{~s}$ (Figure 2). The air temperature rose to a maximum of $327^{\circ} \mathrm{C}$ over the same period of time. Switching the heater on 50 seconds before introducing the sample reduced the heating time to $120^{\circ} \mathrm{C}$ to $14 \mathrm{~s}$ whilst increasing the maximum air temperature to $366^{\circ} \mathrm{C}$ (Figure 3).

When set to 'maximum cooling', the apparatus was capable of cooling the surface of a Tylose sample from 120 to $40^{\circ} \mathrm{C}$ in $28 \mathrm{~s}$ and to $8^{\circ} \mathrm{C}$ in 5 minutes (Figure 4). These data were 
for a sample that had been heated from 5 to $120^{\circ} \mathrm{C}$ in $60 \mathrm{~s}$ with the cooling activated early to pre-cool the delivery hose.

Figure 5 shows a controlled treatment on a Tylose sample with heating settings of 5 to $120^{\circ} \mathrm{C}$ in $120 \mathrm{~s}$, holding for $30 \mathrm{~s}$, cooling to $40^{\circ} \mathrm{C}$ in $90 \mathrm{~s}$ and finally cooling to $10^{\circ} \mathrm{C}$ in a further 270 s with the cooling activated early to pre-cool the delivery hose. The mean and maximum errors (between the control and measured temperatures) were 1.4 and $3.7^{\circ} \mathrm{C}$, respectively, during the heating stage. During the holding stage the mean and maximum errors were 0.9 and $2.6^{\circ} \mathrm{C}$, respectively. During the cooling stages the mean and maximum errors were 3.7 and $42.5^{\circ} \mathrm{C}$, respectively. 'Natural cooling' caused large errors at the beginning of cooling, as the surface cooled rapidly, due to radiation, conduction into the sample and natural convection (air was not blown over the sample when the cooling control was off).

A controlled treatment on a Tylose sample with heating settings of 5 to $60^{\circ} \mathrm{C}$ in $30 \mathrm{~s}$ and holding for $30 \mathrm{~s}$, gave mean errors of 0.8 and $0.7^{\circ} \mathrm{C}$ during the heating and holding, respectively.

\subsection{Wet heating}

It was not possible to deliver superheated steam (above $100^{\circ} \mathrm{C}$ ) to the surface of the sample. A small (4 mm) diameter hose was used to supply the steam from the generator to the steam quadrant. This hose produced a $4 \mathrm{~mm}$ diameter jet of steam (at $107^{\circ} \mathrm{C}$ ) that mixed with the air inside the quadrant almost immediately, reducing the temperature of the jet to between 70 and $80^{\circ} \mathrm{C}$. To counteract this problem, the hose was expanded to $12 \mathrm{~mm}$ diameter and the sample raised $100 \mathrm{~mm}$ closer to the steam nozzle, this meant that the potential core of the jet would reach the sample surface. However, increasing the diameter of the hose reduced the temperature of the steam exiting the nozzle to $100^{\circ} \mathrm{C}$. 
The following results are for the modified steam system with $12 \mathrm{~mm}$ diameter hose and sample closer to the nozzle. From the moment the steam valve was opened, it took $1 \mathrm{~s}$ to deliver steam to the surface of the sample and a further $6 \mathrm{~s}$ for that steam to reach a temperature of $99^{\circ} \mathrm{C}$, by which time the temperature just below the surface of the Teflon sample had reached $90^{\circ} \mathrm{C}$ in the centre and $74^{\circ} \mathrm{C}$ at the edge.

\subsection{Uniformity of heating}

Two methods were used to measure the uniformity of heating. The first was using thermocouples just under the surface of a Teflon sample and the second was using an IR thermal imaging camera.

\subsubsection{Thermocouple method}

To evaluate the temperature uniformity on the surface of a sample, a Teflon sample was used with a thermocouple at the centre and edge, just under the surface (the tip of the thermocouple was just exposed). The advantage of this method was that a history of the temperature uniformity was measured during the entire heating process. However, this method did not provide absolute surface temperatures, as the thermocouples measured a temperature somewhere between the surface temperature and some distance below the surface.

\subsubsection{Thermal imaging method}

A thermal imaging camera (ThermaCam E4, FLIR Systems AB, Sweden) was used to determine the temperatures on the surface of a Teflon sample, after a rapid, high temperature dry heating treatment (20 to $100^{\circ} \mathrm{C}$ in $60 \mathrm{~s}$ ). The camera had been calibrated using radiation sources that are traceable to National Standards. The emissivity of the camera was set to 0.95. It was not possible to take the image to measure temperatures whilst the sample was in 
the chamber and therefore the sample was removed from the apparatus immediately after heating and the thermal image taken within $9 \mathrm{~s}$.

The advantage of this method was that real surface temperatures were measured at all positions on the surface of a sample. The disadvantage was that it was not possible to measure temperature data using the camera during the heating process.

\subsubsection{Dry air treatment}

Figure 6 shows the temperature history during a heat treatment to $100^{\circ} \mathrm{C}$ in $30 \mathrm{~s}$ using the thermocouple method. Results show a maximum difference of $3^{\circ} \mathrm{C}$ between the centre and edge thermocouples.

Figure 7 shows the thermal image $9 \mathrm{~s}$ after a rapid hot air treatment. A hot ring $\left(79^{\circ} \mathrm{C}\right)$ can be seen around the edge of the sample, representing the glass and perhaps the outer edge of the sample. The maximum and minimum temperatures of the bulk of the sample (inside the hot ring) were 70.7 and $69.5^{\circ} \mathrm{C}$ respectively.

The reduced average temperature of the sample (approximately $70^{\circ} \mathrm{C}$ ) represents the rapid cooling of the surface that occurs by conduction from the bulk of the sample to the surface and heat exchange with the environment during the $9 \mathrm{~s}$ between the end of heating and taking the thermal image.

\subsubsection{Wet treatment}

Figure 8 shows the temperature history during a 45 s steam treatment using the thermocouple method. There was a difference in temperature between the edge of the sample and the centre of $4.9^{\circ} \mathrm{C}$ at the end of the treatment. 


\section{Discussion and conclusion}

A bench top apparatus to heat a sample from a given surface temperature at a given rate, hold the sample at a given temperature for a defined period and cool the sample in a controlled manner has been built and its performance evaluated. The apparatus can either heat in a dry (hot air) or wet (steam) manner.

Surface temperatures were measured using calibrated IR thermometers and controlled during the dry experiments.

The apparatus was shown to heat the surface of a Tylose sample from 8 to $120^{\circ} \mathrm{C}$ in $14 \mathrm{~s}$ using dry air at maximum heating. This apparatus was $34 \%$ faster at heating than the previous apparatus for an identical treatment (maximum heating to $100^{\circ} \mathrm{C}$ without preheating).

The apparatus was shown to cool the surface of a Tylose sample from 120 to $40^{\circ} \mathrm{C}$ in $28 \mathrm{~s}$ and to $8^{\circ} \mathrm{C}$ in 5 minutes at maximum cooling, using a modular bench mounted cooling system. Cooling rates were not as high as predicted by the heat transfer model (Kondjoyan et al, 2005), which predicted cooling from 120 to $40^{\circ} \mathrm{C}$ in $15 \mathrm{~s}$ and further cooling to $5^{\circ} \mathrm{C}$ in 300

s. The difference between the conditions used to predict the design data and the measured conditions were that 1) the design conditions had a shorter heating ramp before the cooling (23 rather than 60s) and 2) the design conditions had an air velocity which did not drop with time. The numerical model described earlier showed that these differences account for the difference between the initial, design cooling rates and those measured during the experiments. This apparatus cooled far more effectively than the previous apparatus, which took an extra $23 \mathrm{~s}$ to reach a surface temperature of $40^{\circ} \mathrm{C}$ from a lower starting temperature of $100^{\circ} \mathrm{C}$ and reached a final temperature that was $8^{\circ} \mathrm{C}$ higher after $300 \mathrm{~s}$ of cooling. 
The average control error was generally less than $\pm 1^{\circ} \mathrm{C}$, which was higher than the specification aim of $\pm 0.5^{\circ} \mathrm{C}$ but lower than the original apparatus of approximately $\pm 2{ }^{\circ} \mathrm{C}$. A way of self-tuning of the control parameters during a treatment may have reduced these errors, but this was not realised. Errors were higher during the cooling treatment due to 'natural cooling'. Accurate temperature control during cooling was considered less important as the intention of the cooling was to reduce the surface temperature quickly to avoid further decontamination.

A difference in temperature across the surface of the bulk of the sample $9 \mathrm{~s}$ after heating of only $1.2^{\circ} \mathrm{C}$ was measured. This was only $35 \%$ of the temperature difference recorded in the previous apparatus and was within the design specification of $\pm 1^{\circ} \mathrm{C}$.

Wet heating using steam at $100^{\circ} \mathrm{C}$ was achieved using a portable steam generator. The apparatus was unable to produce superheated steam at $120^{\circ} \mathrm{C}$ to the surface of the sample. Experiments using a heated hose (hose heated to same temperature as water in steam generator) between the steam generator and chamber have shown the possibility of providing superheated steam to the chamber, however this has not been incorporated in this apparatus.

The price of the parts which made up the apparatus were approximately $€ 10000$, taking approximately two person-weeks to build. The authors believe a commercial unit would be cost effective.

\section{Acknowledgements}

This work was funded as part of the European Union Framework Five project "Bugdeath" QLRT-2001-01415. We acknowledge the close collaboration of all the partners in this project. Finally, we thank Trevor Delves a visiting worker from Charles Sturt University, Australia who helped in the design of the refrigeration equipment. 


\section{References}

Foster, A.M., Ketteringham, L.K., Swain, M.J., Kondjoyan, A., Havet, M., Rouaud, O. \& Evans J.A (2005). Design and development of apparatus to provide repeatable surface temperature-time treatments on inoculated food samples. J of Food Engineering, Vol. 76, Number 12006 (Published 10 April 2006).

Kondjoyan, A., Rouaud, O., McCann, M., Havet M., Foster, A., Swain, M., \& Daudin, J.D. (2005). Modelling coupled heat-water transfers during a decontamination treatment of the surface of solid food products by a jet of hot air - I. Sensitivity analysis of the model and first validations of product surface temperature under constant air temperature conditions. J of Food Engineering, Vol. 76, Number 12006 (Published 10 April 2006).

Lewis, R.J., Baldwin A., O'Neill, T., Alloush, H., Nelson, S.M., Dowman A. \& Salisbury, V. (2005). Use of Salmonella enterica serovar Typhimurium DT104 expressing lux genes to assess, in real time and in situ, heat inactivation and recovery on a range of contaminated food surfaces. J of Food Engineering, Vol. 76, Number 1 2006 (Published 10 April 2006).

Rajaratnam, N. (1976). Turbulent jets. Developments in Water Science. Elsevier Scientific Publishing Co.

Riedel, L. (1960) Eine prüfsubstanz für gefrierversuche (A test substance for freezing experiments), Kältetechnik, 12 Jahrgang, Vol. 8, pp222-225.

Soto, V. \& Borquez, R (2001). Impingement freezing of biomaterials. Food Control 12,515-522 


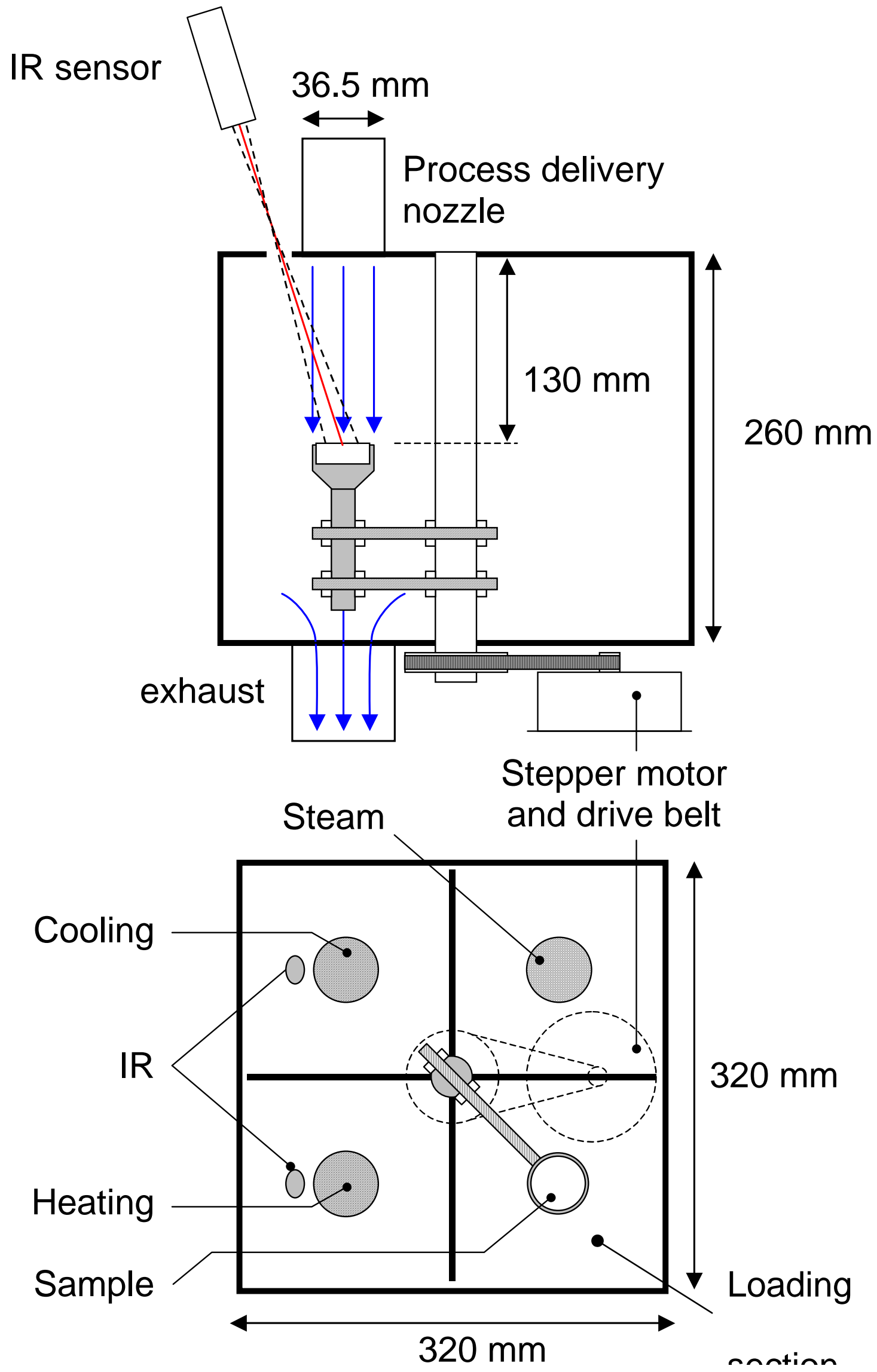

Figure 1. Vertical section (top) and plan view (bottom) of the new apparatus. 


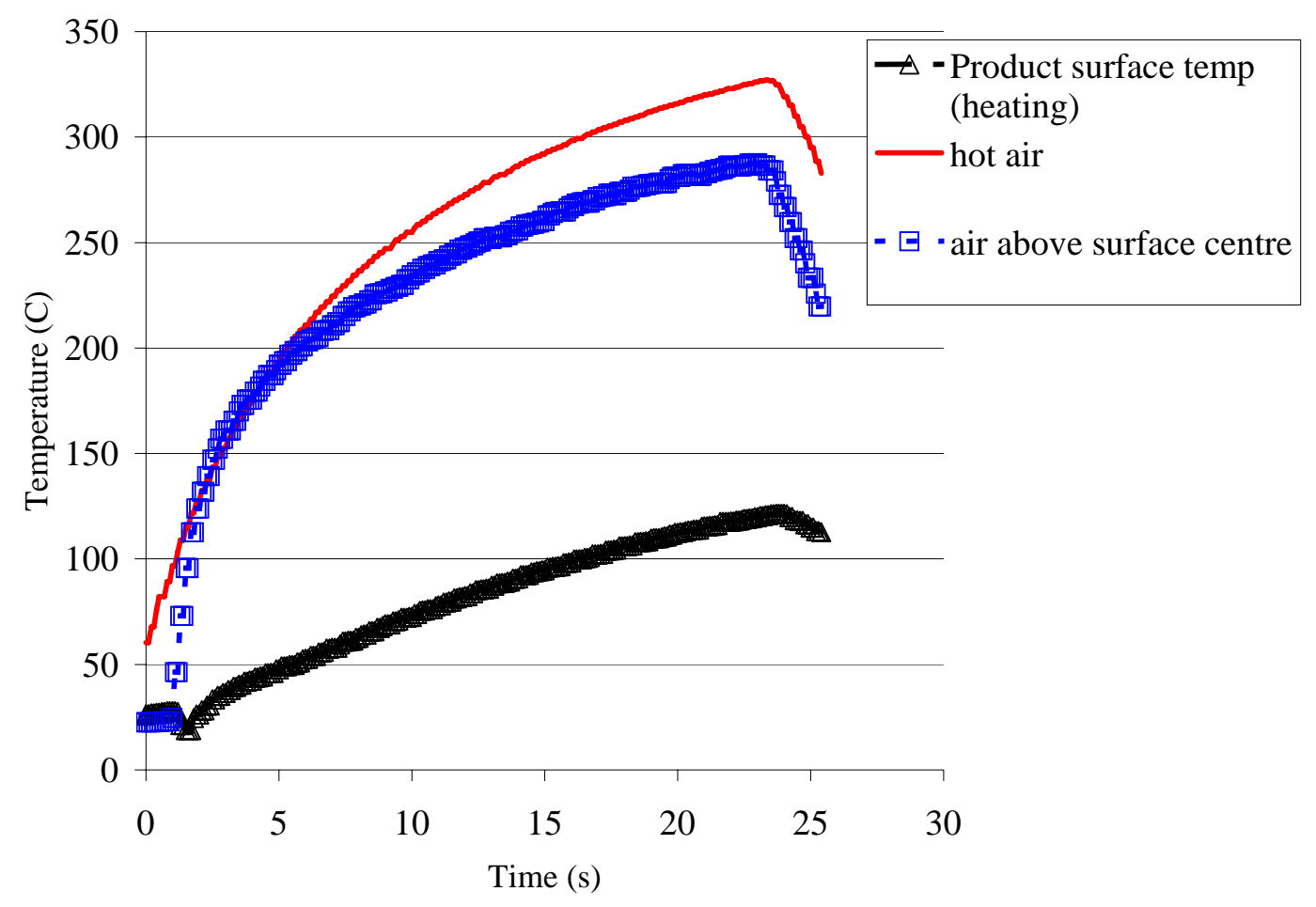

Figure 2. Temperatures measured on the surface of a Tylose sample, the air just above the surface and the air exiting the heater nozzle for a maximum heating (uncontrolled) treatment. 


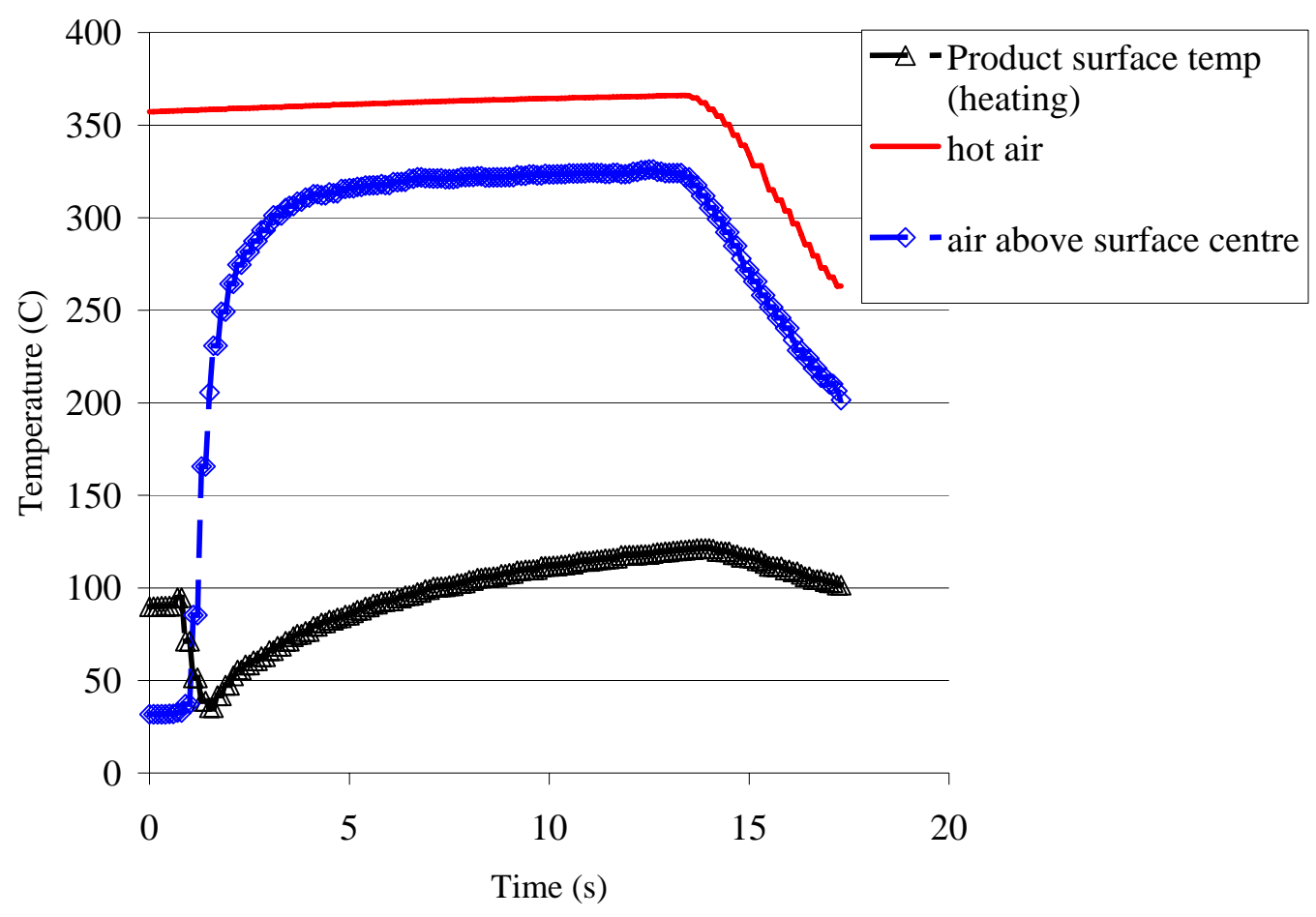

Figure 3. Temperatures measured on the surface of a Tylose sample, the air just above the surface and the air exiting the heater nozzle for a maximum heating (uncontrolled) treatment with a preheating time of $50 \mathrm{~s}$. 


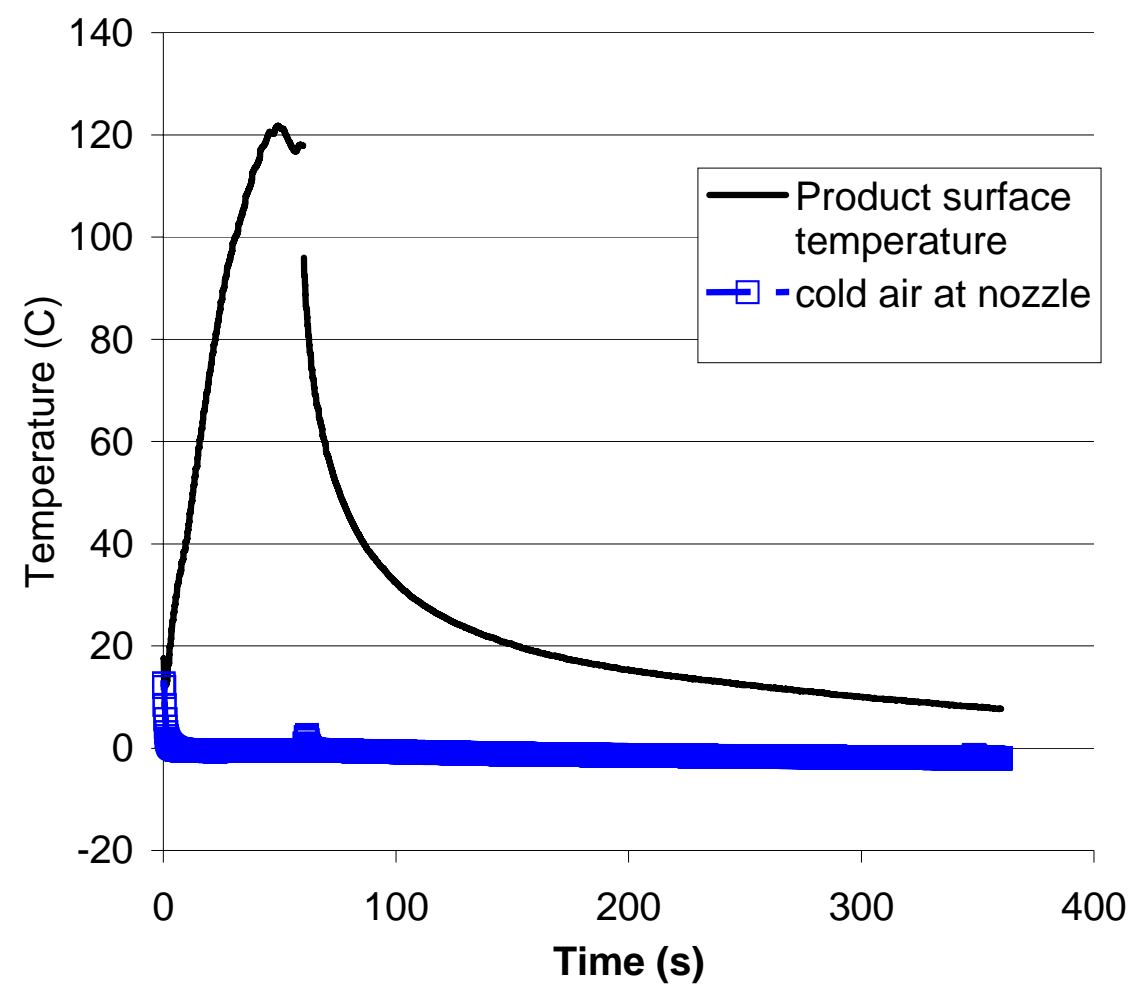

Figure 4. Temperatures measured on the surface of a Tylose sample and the air exiting the heater and cooler nozzle for a maximum cooling (uncontrolled) treatment. 


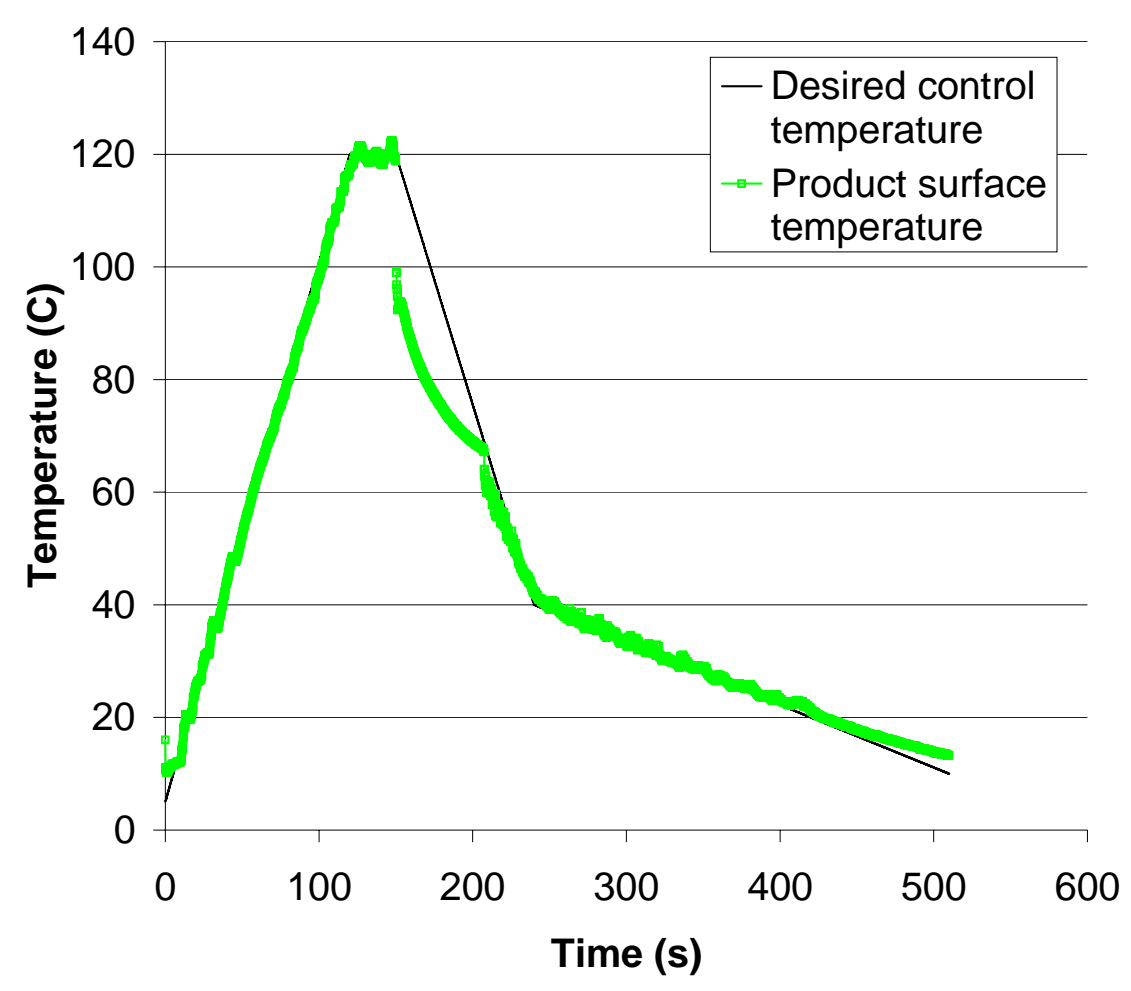

Figure 5. Temperatures measured on the surface of a Tylose sample and the desired control temperature for a controlled heating/holding/cooling treatment. The treatment settings were 5 to $120^{\circ} \mathrm{C}$ in $120 \mathrm{~s}$, holding for $20 \mathrm{~s} 120^{\circ} \mathrm{C}$ to $40^{\circ} \mathrm{C}$ in 90 s and cooling to $5^{\circ} \mathrm{C}$ in a further 270 S. 


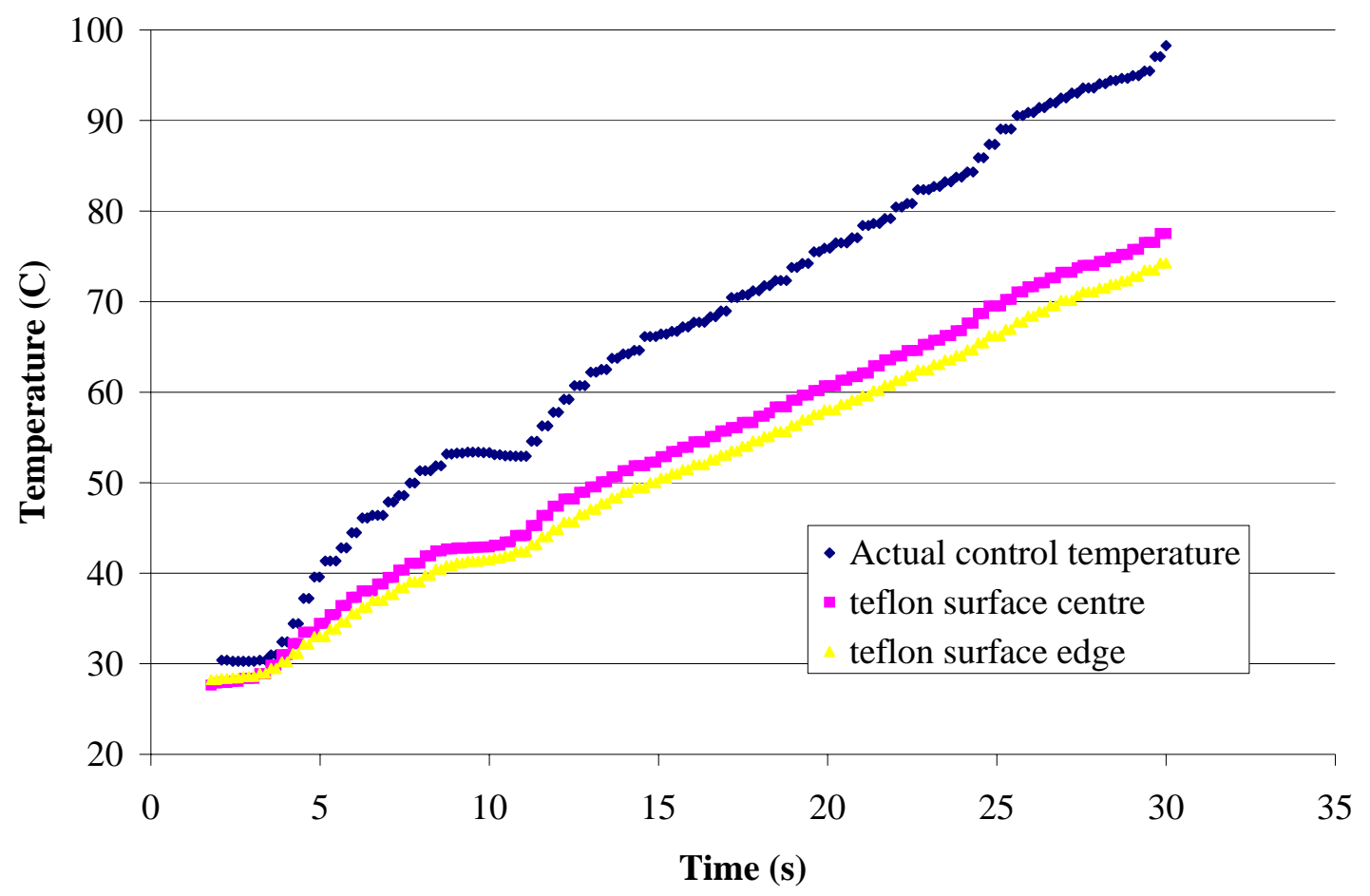

Figure 6. Temperatures measured on the surface of a Teflon sample at the centre and edge and with the IR sensor (actual control temperature) during a dry heat treatment to $100^{\circ} \mathrm{C}$ in $30 \mathrm{~s}$. 


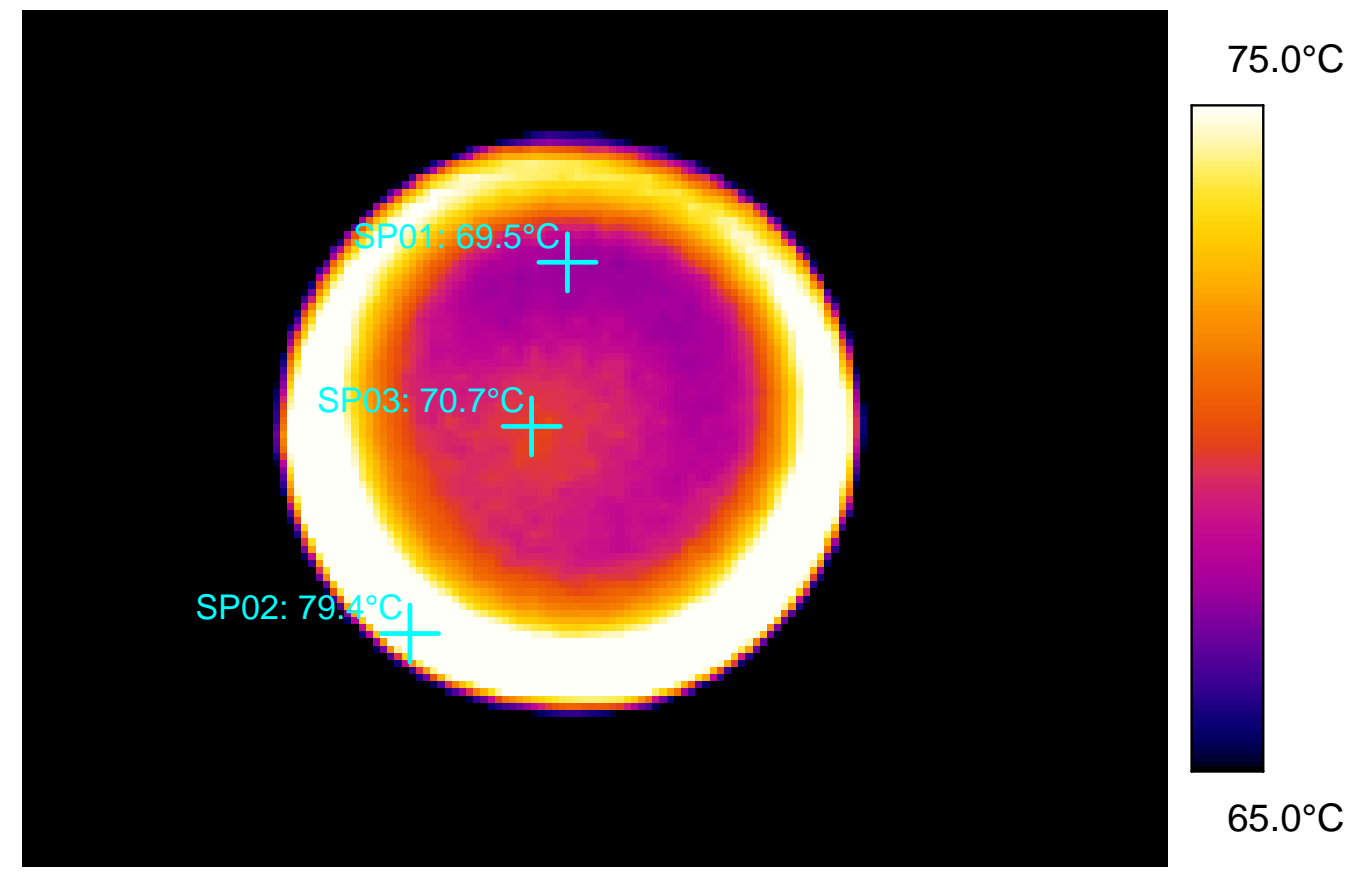

Figure 7. Temperature uniformity on the surface a Teflon sample taken by a thermal imaging camera, $9 \mathrm{~s}$ after heating to $100^{\circ} \mathrm{C}$ in $60 \mathrm{~s}$. 


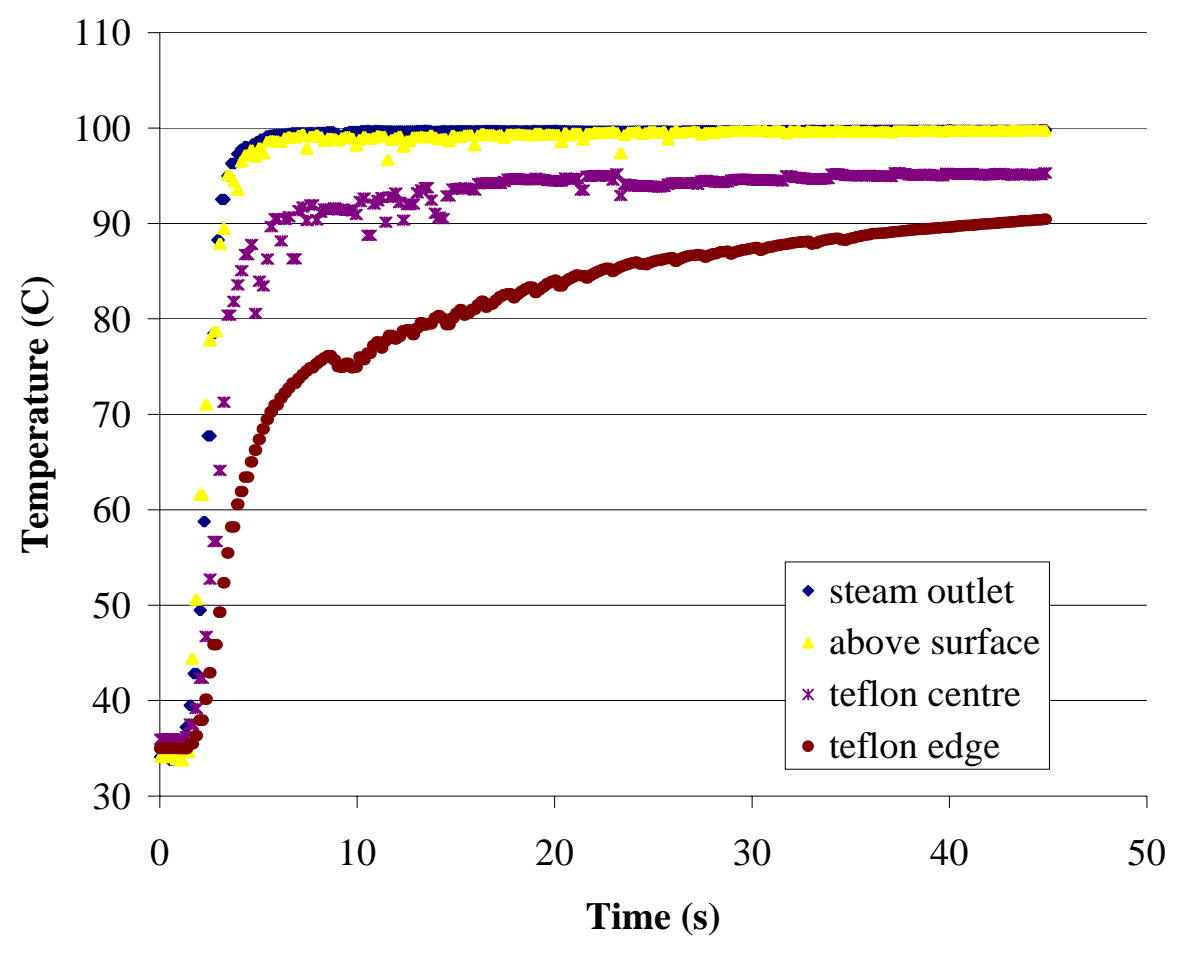

Figure 8. Temperatures measured just under the surface of a Teflon sample at the centre and edge, just above the surface and the steam exiting the nozzle during a steam treatment. 